ERRATUM

Shane D. Roberts · Mark D. Powell

\title{
The viscosity and glycoprotein biochemistry of salmonid mucus varies with species, salinity and the presence of amoebic gill disease
}

\section{J Comp Physiol B (2004) 175:1-11}

Figure 2 should read: "mOsmol kg $\mathrm{kg}^{-1}$ " as its units instead of "osmole $\mathrm{kg}^{-1}$ ":

The online version of the original article can be found at http:// dx.doi.org/10.1007/s00360-004-0453-1

S. D. Roberts $(\bowtie) \cdot$ M. D. Powell

School of Aquaculture, Tasmanian Aquaculture and Fisheries

Institute, University of Tasmania, Locked Bag 1370 ,

7250 Launceston, Tasmania, Australia

E-mail: roberts.shane@saugov.sa.gov.au

Tel.: + 61-8-86832524

Fax: $+61-8-86832520$

S. D. Roberts · M. D. Powell

Cooperative Research Centre for Sustainable Aquaculture of Finfish, West Beach, South Australia, Australia

Present address: S. D. Roberts

South Australian Research and Development Institute,

Lincoln Marine Science Centre, P.O. Box 1511,

5606 Port Lincoln, South Australia, Australia
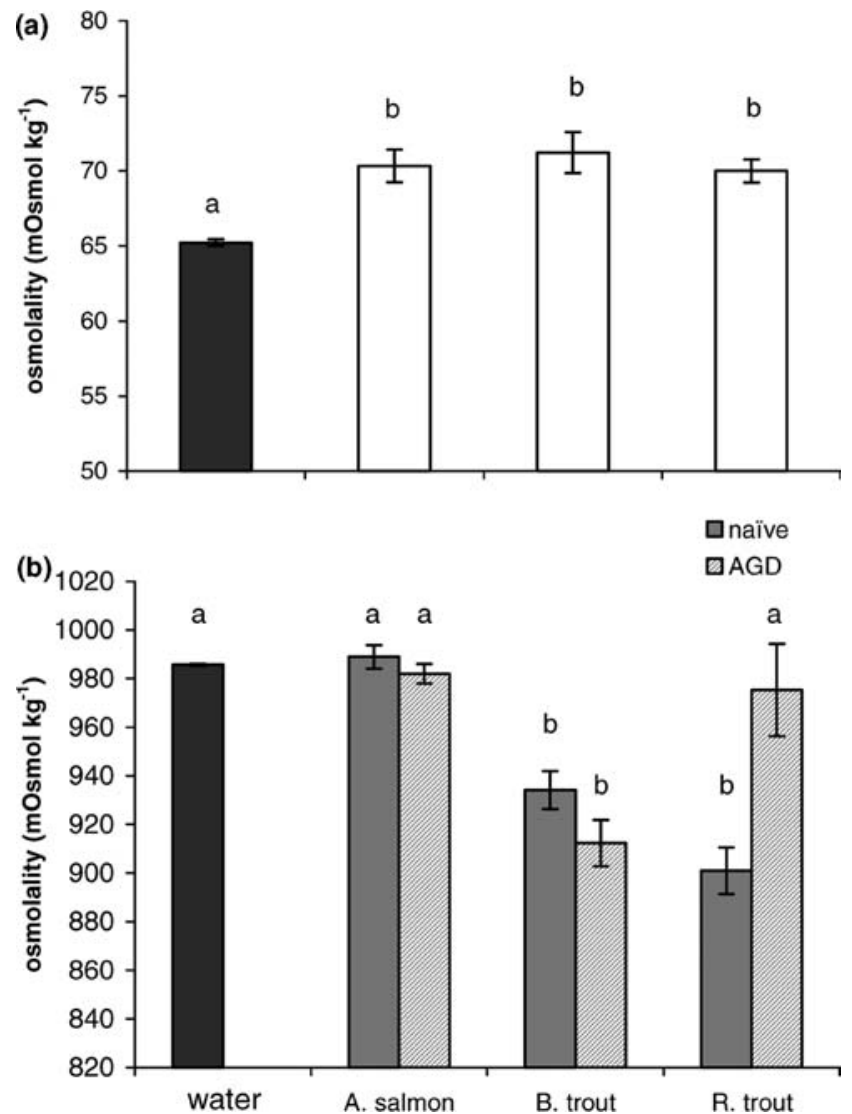

Fig. 2 Osmolality of water and fish cutaneous mucus for a freshwater $(n=12)$ and b seawater $(n=26)$, including both AGDnaïve and affected, fish (mean $\pm \mathrm{SE}$ ). Data show osmolality for Atlantic salmon, brown trout and rainbow trout mucus. Different letters indicate significant differences between treatment means $(P<0.05)$ 